\title{
Introduction
}

A question permeates much comparative political economy from the classics to contemporary scholarship: how is it possible to combine capitalism with democracy? Torben Iversen (2006, p. 601)

\section{MAIN ISSUES}

Iversen's question takes a central place in our book. The friction between capitalism and democracy can be explained as follows. Capitalism generates strong inequalities in the distribution of income and wealth, while democracy divides political power in an egalitarian manner, under the principle of one person, one vote. The majority may vote in favour of redistributing income, and maybe wealth, from the rich to the poor. But then the rich will resist by disputing the political power of the majority or by curtailing their economic efforts. The consequences of such a struggle are serious and may influence the viability of the capitalist system.

There is another aspect in the quotation above that needs attention. Iversen refers to political economy but in economics, as the discipline is usually called, there is no attention to the distribution of income and wealth. In the dominant neoclassical theory emphasis is on the efficient allocation of the production factors, taking account of the preferences of economic subjects. Who owns these factors and receives the factor incomes is irrelevant in this theory.

To understand why capitalism produces inequality a different approach to studying the process of supplying goods and services is in order. Capitalism implies that the owners of capital have the freedom to organize the production process to make as much profit as possible. Moreover, competition forces capitalists to innovate new production methods or new production processes which lead to temporary monopoly positions. This process is reinforced by applying every opportunity to take advantage of economies of scale with respect to the technological possibilities but also with respect to the organization of enterprises. Not every attempt to generate profits is successful. Moreover, existing economic activities may be outcompeted by new developments. Such events are referred to as acts 
of creative destruction. In the on-going process of capital accumulation there are always winners and losers. Losers may try to improve their fate. The question is then: what means do they have to change the course of development?

Redistribution of income through the political system is a possibility, as mentioned above. However, the problem should be placed in a much broader perspective. The relentless accumulation of capital is constrained by a set of rules. These rules of the game consist of laws, conventions and beliefs. It is customary to indicate these constraints on economic activities as economic institutions. Institutional economics analyzes the manner in which the rules of the game determine capital accumulation, economic growth and the distribution of income. After a long period of standing in the shadow institutional economics has regained the prominent place it had in the past. However, this approach is not sufficient. Institutions are man-made and how they come into existence must be analyzed. This task brings us back to the realm of political economy.

An important lesson of political economy is that there is a close connection between capitalism and democracy that goes both ways. Economic institutions and the redistribution of income are determined according to the distribution of political power. Political power depends on existing political institutions, such as the constitution and voting rules for parliament, and on the investments in political power by economic agents with sufficient wealth. Such investments may be profitable if the economic institutions can be changed in a way that is beneficial to the investors. Investments in political power can take very different forms. There are historical examples of landowners buying the votes of their labourers. In modern times capitalists may financially support political parties with programs that are attractive to them or spend funds for lobbying among politicians and civil servants. Moreover, capitalists may invest in public communication channels which may be profitable and at the same time instrumental in influencing the public opinion in a preferred manner. Moreover, it may be rewarding to join economic and political elites. The revolving door policy in the appointment of people in high places in business as well as in politics is a way of materializing such cooperation.

It should be noted that not all economic institutions can be adapted in the short-run. There is a certain degree of path-dependency, implying that institutional differences across countries are to some extent the result of decisions made in the past. Therefore, historical constraints have to be taken into account in political economy. In this connection it is important to observe that the capitalistic system is rather young. It emerged along with the Industrial Revolution in England after 1750. Before this event economic activities were embedded in social relations. The separation of 
society into an economic and political sphere is marked by Karl Polanyi (1944) as 'The Great Transformation', which paved the way for a selfregulating market system. Polanyi prefers the latter term to the now prevalent term capitalism.

The Industrial Revolution was made possible by ensuring property rights of merchants and entrepreneurs, without relying on a fully developed democracy. This is an important observation, because we will return to the question of whether capitalism and democracy have to go hand-inhand in the course of our considerations. The coexistence of capitalism and democracy is not a matter of necessity as recent developments, for instance in China, make clear. The fast growth of the Chinese economy has been possible without the support of a democratic political regime. Nevertheless, secure property rights are a necessary condition for economic development in all circumstances.

Capitalist accumulation accompanied by Darwinian competition has brought a high level of welfare into the Western world. At the same time an uncontrolled form of capitalism is inherently unstable. This concerns not only financial instability but goes much deeper. The forces behind the relentless accumulation of capital are strong enough to erode the moral foundations of society. The process of creative destruction reaches further than the elimination of declining industries. The market system needs some form of regulation. This is part of what Polanyi (1944) calls the 'double movement'. On the one hand, for the market system to flourish capitalists and entrepreneurs need the freedom to experiment and to change things. On the other hand, society must protect itself for the pernicious effects of relentless accumulation. How this tension inherent in the capitalist system is solved must be revealed by studying economic history. However, at this point we encounter a methodological problem. As emphasized by Joseph Schumpeter (1942), a pure description of the facts without applying the results of rigorous economic theory is not sufficient. In the words of Schumpeter (1942, p. 44) one has to determine 'how economic theory may be turned into historical analysis and how the historical narrative may be turned into histoire raisonnée'. This is not an easy task as there are no rules to stick to.

According to Karl Gunnar Persson (2010) economic history traces the efficiency aspects of institutions by studying markets, property rights, and incentives of economic agents. Efficiency considerations are important without any doubt and many institutions make a significant contribution to the efficient allocation of the means of production. However, the concept of economic history as conceived by Persson is too narrow. Special interest groups with political power may extract rents from productive sectors in the economy for their own well-being. Moreover, social 
conflicts regarding the distribution of income are an important aspect of real life. More than that, the question of institutional origins needs to be considered, which often cannot be done without taking into account the historical conditions that give rise to them. To proceed in this direction Iversen (2006) stresses the idea of rooting actors in the structure of the capitalist economy. The project is referred to as 'new structuralism', whereby the success 'will depend on combining carefully identified historical constraints with rigorous theorizing' (Iversen, 2006, p. 618).

With this statement in mind, we proceed by introducing a dialectic approach. In Part I of this book economic theory is discussed in a historical perspective. The theories selected for discussion are relevant for understanding historical developments. In Part II of our study emphasis lies on historical developments in a theoretical perspective. The theoretical results obtained in Part I are applied to interpret the observed historical facts. Each part contains four chapters. The main question of how capitalism and democracy are combined is worked out in two directions. First, we analyze the double movement, as identified in Polanyi (1944), in the context of the leading countries in the capitalist system. Here leadership is defined in technological terms. The leading country operates on the technological frontier. In this sense the leader stands for capitalism in its most advanced form. Second, we investigate the consequences of introducing capitalism in different parts of the world. The Industrial Revolution started in England, while other European countries followed in due time. Throughout the rest of the world the process of industrialization had to wait for a much longer time. Lagging behind implies that technology and institutions can be imitated from the leading country. Whether the catching-up process leads to a uniform global pattern or to varieties of capitalism in separate countries, with diverging economic and political institutions, is an important issue that deserves close scrutiny.

\section{OUTLINE OF CHAPTERS}

To explain the design of the book we present a short outline of the different chapters. Several economic theories are considered in Part I. In Chapter 1 the genesis of capitalism is discussed. The 'Great Transformation', in the terminology of Polanyi (1944), marks the beginning of the self-regulating market system by setting the political rulers at a distance. To eliminate the possibility of expropriation property coercion-constraining institutions have to be installed, as Avner Greif (2008) emphasizes. In addition, contract-enforcement institutions are needed to regulate production and trade. Contract-enforcing institutions can be installed by private parties 
or have a public character when regulation is enforced by the government. With the right mix of both types of institution the market system will flourish. However, this is not the end of the story. Since the Industrial Revolution in England capitalist development is based on technological change and creative destruction. As a result, things may run out of hand. Speculation, inequality and exclusion may undermine the stability of the system. Under these circumstances additional regulation is called for. This implies that a double movement exists in the words of Polanyi (1944), characterizing the design of the economy. Property rights and freedom of enterprise are necessary to foster innovation and economic growth. However, too much freedom can lead to aberrations, which need to be corrected by imposing appropriate rules.

The discussion in Chapter 1 makes clear that economic activities and political decision-making are interconnected. To analyze the implications of this symbiotic relationship we have to turn to the field of political economy. As Edward Glaeser (2005, p.2) observes rightly: 'The insight that economics impacts politics as much as politics impacts economics lies at the heart of political economy'. Chapter 2 is devoted to an overview of the field. After positioning the process of allocation of the means of production in society at large, we turn to a discussion of formal models of political economy. As shown in Daron Acemoglu (2009) the allocation of production factors and the resulting distribution of incomes depend upon the political regime. Elites dominating the economy will extract rents by taxing productive activities. 'Business elites' will even impose higher taxes than pure political elites, as explained in François Bourguignon and Thierry Verdier (2010). Business elites also may invest in state capacity building to increase the revenues from rent extraction. In the case of a probability of losing power, elites will react by taking measures to prevent the shifting of power to the workers. The analysis becomes more complicated when political power between the elites and workers switches according to a stochastic pattern. In the model by Daron Acemoglu and James Robinson (2008) stochastic regimes switches occur between oligarchy with exploitation of workers and democracy with workers paid according to their marginal products. Such switches resemble, to a certain extent, the double movement as conceived by Polanyi. However, the dynamic forces of capitalism in the form of capital accumulation and technological change are not taken into account. To fill this gap we discuss the history of the US economy. The relevance of the double movement is illustrated by showing that plutocratic periods with unrestrained capital accumulation alternate with democratic periods exhibiting more regulation of markets. In sum, one could say that both methods, modelling and description, each in their own way elucidate what is at stake in political economy. 
Technological change is the driving force of accumulation and growth in the capitalist system. In Chapter 3 we survey the different approaches dealing with this phenomenon. In the traditional neoclassical growth theory technological change is conceived as an exogenous factor. In the more recent literature technological change is explained by factors like learning-by-doing and investment in research and development. However, in most of the models technological change appears as a smooth process so that balanced growth paths with constant growth rates of the key variables can be obtained. Such a reassuring picture changes dramatically when the abrupt introduction of general purpose technologies (GPTs) is considered. A GPT is a technological innovation in the form of process innovation, product innovation or an organizational breakthrough with great potential of its own and numerous other applications and spillovers to other sectors. As shown in the model of Elhanan Helpman and Manuel Trajtenberg (1998) the introduction of a GPT may lead to a temporary growth slowdown, because a new constellation of productive activities has to be built. In the model the introduction of a new GPT requires the production of related input components, which takes time. However, the appearance of a new GPT induces changes in many aspects of daily life, like for instance capital accumulation, education, infrastructure, corporate governance and so on. Moreover, the introduction of GPTs follows a certain pattern over time, which can be illustrated with the logistic curve. GPTs may also overlap and reinforce one another. In short, to understand the full meaning of general purpose technologies a descriptive analysis, or appreciative theorizing in the terminology of Richard Lipsey, Kenneth Carlaw and Clifford Bekar (2005), is again of vital importance.

For backward economies technological change is, to a large extent, dominated by catching-up with the leader. As shown in Chapter 4, catching-up implies a growth rate of GDP per capita in excess of that of the technological leader. As the process evolves, the growth rate of the backward economy slows down to the level attained in the leading country. Nevertheless convergence may be incomplete in terms of the level of per capita GDP, if the initially backward country fails to make the required adaptions in due time. What this may mean, is illustrated in a sophisticated model constructed by Daron Acemoglu, Philippe Aghion and Fabrizio Zilibotti (2006). To realize complete convergence backward countries have to switch in time from an investment-based strategy towards an innovation-based strategy. The investment-based strategy is based on long-term relationships and large-scale investment projects. In the case of an innovation-based strategy the selection of managers with innovative capabilities is at the centre of economic activities. The 
decision to switch toward an innovation-based strategy is made by profitmaximizing capitalists, but institutions play a role in the background.

The government may make the investment-based strategy more attractive by subsidizing investment or by restricting competition. Less competition implies higher profits and therefore less reason to alter the strategy. The problems that backward economies have to cope with are more extensive than appears from a macroeconomic approach. Structural transformations with respect to the sector structure and the mobility of production factors that are rather drastic have to be made. Here again the government may play a vital role by stimulating the required changes. However, it should be stressed that institutions also have to be adapted when they are no longer efficient. Whether this will take place depends upon the political constellation and the political power of the groups concerned.

In Part II historical developments in a world characterized by capitalism are put in the forefront. The existence, meaning and impact of long waves of approximately 50 years are considered in Chapter 5 . The existence of long waves is much disputed. There are two ways to proceed if one wants to show that long waves are an essential element of capitalist development. The direct method applies statistical techniques to time series of macroeconomic data to identify cyclical patterns. A recent example of the approach is a study by Andrey Korotayev and Sergey Tsirel (2010), using spectral analysis to decompose time series of the growth rate of world output into cycles of different amplitude and length. The authors show that for the period 1820-2007 five long waves, or Kondratieff-waves as they call them, can be discerned. However, the direct method offers no clues with respect to the factors causing the Kondratieff waves. Moreover, testing the hypothesis of the existence of long waves by applying the growth rate of world output seems rather farfetched. The indirect method of identifying long waves overcomes these drawbacks. The basic idea here is that long waves are caused by technological revolutions. This implies that to find evidence for long waves one has to look at developments in countries that are the technological leaders. Another implication is that one has to trace down the technological features which shape the history of frontier economies. Chris Freeman and Francisco Louçã (2001) identify long waves applying concepts like the constellation of technical innovations, carrier branches, core inputs, infrastructure and organizational changes. They also distinguish five Kondratieff-cycles. Carlota Perez (2002) finds similar results, but comes to a slightly different dating by emphasizing the idea that long waves are the result of the introduction of general purpose technologies with properties discussed in Chapter 3 .

In another approach the existence of long waves is explained by the financial instability hypothesis of Hyman Minsky (1964). According to 
this view firms and banks take an overly optimistic view when the economy flourishes. Too much debt is incurred giving rise to asset bubbles, which burst as the real economy shows signs of stagnation. Ideally, the theories about technological revolutions and financial instability should be combined. However, until now no satisfactory attempts have been made, but Perez (2002) seeks to integrate financial developments into her theory, based on the appearance of GPTs. Although the existence of long waves as such remains under discussion the different theories and empirical observations reveal that the capitalist system is marked by forms of instability in the long run. This observation is corroborated by a periodization of capitalism, which builds upon the results presented in Chapter 2. The cyclical pattern in the real sphere of the economy is reflected in the political field, thus giving rise to a 'double movement' in the sense of Polanyi (1944).

In Chapter 6 capitalist developments in Europe and the US are compared. Somewhere around 1900 technological leadership shifted from England to the US. During the third great surge (1875-1928), in the terminology of Perez (2002), England failed to invest in new industrial sectors such as electricity, steel and chemistry. In the other European countries industrialization started later than in England. The Great Depression and the Second World War set the European countries at a great distance from the US in terms of productivity (production per hour). Catching-up with technological leader only occurred after 1950. Meanwhile the political power in Europe had shifted towards the left as labour unions and socialist parties gained political influence. According to Alberto Alesina and Edward Glaeser (2004) this was a result of the turmoil caused by the First World War. As a consequence, the welfare state was installed in Europe with a substantial redistribution from the rich to the poor in the form of transfers and social insurance. The differences with respect to redistribution show that capitalism can be designed in different ways. However, the discussion under the heading 'varieties of capitalism' mainly deals with differences with respect to the coordination of economic activities.

Peter Hall and David Soskice (2001) set the tone by distinguishing liberal market economies and coordinated market economies. In liberal market economies coordination in the sphere of corporate governance and labour relations is based on competitive market arrangements. In coordinated market economies coordination is to a large extent based on incomplete contracting, network monitoring and collaborative relationships. The group of liberal market economies consists of the Anglo-Saxon countries, whereas the group of coordinated market economies is composed of continental West-European countries supplemented by Japan. In the economic literature there is much discussion on the fundamental 
problem of whether the continental European model, also referred to as the Rhineland model, performs worse in macroeconomics terms than the Anglo-Saxon model with unconstrained markets. Empirical research does not lead to a definitive result. However, the discussion parallels the one in Chapter 4 with respect to the change from an investment-based strategy towards an innovation-based strategy in the case where convergence is under way. Therefore, the main issue is whether capitalist economies should be designed strictly as liberal market economies once innovation becomes the driving force of economic expansion.

Catching-up in the world at large is analyzed in Chapter 7. As unconditional convergence is not found on a macroeconomic level one could look for conditions that must be taken into account when studying the catching-up of a large sample of countries in the second half of the twentieth century. Barry Bosworth and Susan Collins (2003) present an update showing that convergence ultimately depends on where the individual countries stand initially. In contrast, Margaret McMillan and Dani Rodrik (2011) show that even unconditional convergence can be shown in manufacturing sectors. The authors restrict the analysis to the recent period of intensive globalization, 1990-2007, and apply a sample of only 38 countries. As manufacturing sectors exhibit relatively large productivity increases, economic development is stimulated by the expansion of these sectors. If labour is displaced from highly productive sectors towards activities with lower productivity the economy-wide growth suffers. McMillan and Rodrik show that this is the case in Latin America and Africa, while in Asia structural change increases the growth rate of the economy. The difference is explained by the policies followed in the countries concerned. For instance, the Chinese authorities want their dynamic sectors to be competitive in the world market, which can be accomplished by an undervaluation of the real exchange rate. In contrast, in Latin America and Africa overvaluation of the real exchange rate squeezes profits in traditional industries operating at tight profit margins in the world market.

Catching-up is self-limiting. Growth rates decline as progress is made. Barry Eichengreen, Donghyun Park and Kwanho Shin (2011) estimate the chance of a substantial growth slowdown applying a sample with a large number of countries. The chances of such a slowdown depend on per capita GDP and a number of other variables, such as openness to trade, the composition of spending and the pre-slowdown rate of growth. Applying the results to China, it is found that the chance that China will have to face a growth slowdown in the near future is 73 per cent. This result is not in accordance with other empirical studies, which project high growth rates for the Chinese economy in the foreseeable future. Whether 
developing economies will start or continue to catch up with the leading countries is of utmost importance, as it influences the balance of power and cooperation of countries at a global level.

Patterns of international cooperation and the implications for democracy are discussed in Chapter 8. According to Dani Rodrik (2011a) countries have to choose between three alternatives. Globalization in the sense of full-scale market liberalization can be realized in two ways. First, countries can give up a significant part of their national sovereignty. Second, globalization can be combined with the nation state if democracy is kept at bay. The third possibility is to reject, what Rodrik calls hyperglobalization in order to rescue democracy. In the latter case one settles for a 'thin' or 'sane' version of globalization, meaning that countries maintain the right to protect their own social arrangements, regulations and institutions. The purpose of international economic arrangements is then to determine the rules for managing the interface among national institutions. The big question is of course whether countries really have that choice or whether they have to accept hyperglobalization under the pressure of international competition. What is at stake is revealed on a smaller scale by the problems surrounding the economic integration of Europe. In this respect the viability of the European Monetary Union (EMU) is of special interest. A monetary union or currency area without political unification invites trouble. This is certainly true when core EMUcountries and periphery-countries face diverging price levels. As a consequence of too high price levels in the periphery the real problem is a lack of competitiveness of the latter group of countries. This implies that the debt crisis is in essence a balance-of-payments crisis in the GIIPS-countries (Greece, Italy, Ireland, Portugal and Spain). Hans-Werner Sinn (2011) proposes a number of measures to restore market discipline in these countries, and to provide temporary help. However, to really rescue the euro it may be necessary to give up a part of the sovereignty. To a certain extent this already applies in the context of the European Union (EU). In fact as Charles Sabel and Jonathan Zeitlin (2007) argue, the EU is already in a stage characterized by a 'new architecture of experimentalist governance'. In this respect Europe may be considered as a forerunner in the search for new forms of international cooperation.

It is also interesting to speculate what will happen in China. Will there be another variety of capitalism, not routed in democracy, but characterized by Confucian values? According to Christopher McNally (2011) Guanxi capitalism with a 'deliberate ambiguity' in human relations is a Chinese variety of state capitalism, which may survive in the future. That China will remain different for a long time to come is corroborated by Martin Jacques (2009) in his penetrating study of the Chinese culture. 
The implications for international economic cooperation are difficult to guess but the role of China will be prominent as Jacques (2009, p. 431) emphasizes: 'A nation that comprises one-fifth of the world's population is already in the process of transforming the workings of the global economy and its structure of power'. 
Theo C.M.J. van de Klundert - 9781781956168 Downloaded from PubFactory at $04 / 26 / 2023$ 01:37:24PM via free access 